\title{
Señalización asociada al receptor del factor de crecimiento similar a la insulina de tipo I en una línea celular colombiana de carcinoma mamario
}

\author{
Wilson Mejía1, Carlos Castro², Adriana Umaña², Clemencia de Castro³, \\ Tulia Riveros ${ }^{3}$, Myriam Sánchez-Gómez² \\ 1 Departamento de Nutrición y Bioquímica, Facultad de Ciencias, Pontificia Universidad Javeriana, Bogotá, D.C., \\ Colombia \\ 2 Laboratorio de Hormonas, Departamento de Química, Facultad de Ciencias, Universidad Nacional de Colombia, \\ Bogotá, D.C., Colombia \\ ${ }^{3}$ Facultad de Medicina, Universidad San Martín, Bogotá, D.C., Colombia
}

Introducción. Varios estudios in vitro sugieren que la proliferación, migración y supervivencia en líneas celulares de cáncer de seno se ven significativamente afectadas por la activación del receptor IGF de tipo I (Insulin-like Growth Factor-I Receptor, IGF-IR).

Objetivo. Caracterizar la fosforilación del IGF-IR y las moléculas de señalización intracelular Akt y Erk1/2 (vías de señalización PI-3K y MAPK, respectivamente), causada por el factor IGF-I en una línea celular colombiana de cáncer de mama ductal infiltrante (CSC 1595).

Materiales y métodos. Las líneas celulares CSC 1595 y MCF-7 se cultivaron en medio DMEM con suplemento de suero fetal bovino 10\%, glutamina $2 \mathrm{mM}$, penicilina $100 \mathrm{U} / \mathrm{ml}$, estreptomicina $100 \mu \mathrm{g} /$ $\mathrm{ml}$ a $37{ }^{\circ} \mathrm{C}$, atmósfera de $\mathrm{CO}_{2}$ al $5 \%$ y humedad de $95 \%$. Los extractos celulares se sometieron a inmunoprecipitación e inmunodetección con anticuerpos específicos anti-pIGF-IR, anti-pERK1/2 y antipAkt.

Resultados. Cinco minutos después del estímulo con 10 nM de IGF-I, 70\% y 25\% del IGF-IR fueron fosforilados en las células CSC 1595 y MCF-7, respectivamente; también se observó activación de las proteínas Akt y ERK1/2. Los niveles basales y estimulados de las proteínas ERK1/2 fueron significativamente más altos en las células CSC 1595, comparados a los observados en MCF-7.

Conclusiones. EI IGF-IR y la vía MAPK cinasa que involucra las proteínas ERK1/2 muestran una fosforilación mayor en las células 1595 a la observada en las MCF-7. EI IGF-IR, principal activador de esta vía, podría jugar un papel importante en los procesos de proliferación y metástasis de tumores de cáncer de mama ductal infiltrante.

Palabras clave: neoplasias de la mama, línea celular, receptor IGF de tipo 1, proteína cinasa 1 activada por mitógenos, 1-fosfatidilinositol 3-cinasa, proteína oncogénica v-akt.

Insulin-like growth factor receptor I signaling in a breast cancer cell line

Introduction. In vitro studies strongly suggest that proliferation, migration and cell survival of breast cancer cell lines are significantly affected by activation of the IGF type 1 receptor (IGF-IR).

Objective. The phosphorylation by IGF-I of IGF-IR and the intracellular signaling molecules Akt (PI-3K pathway) and Erk1/2 (MAPK pathway) was characterized in a human breast cancer cell lines.

Materials and methods. The study compared a standard breast adenocarcinoma line (MCF-7) cell line with a line (CSC 1595) derived from an infiltrating ductal breast cancer in a Colombian patient. The CSC 1595 and MCF-7 cell lines were cultured in DMEM supplemented with 10\% fetal bovine serum, 2 mM glutamine, $100 \mathrm{U} / \mathrm{ml}$ penicillin, and $100 \mu \mathrm{g} / \mathrm{ml}$ streptomycin and grown at $37^{\circ} \mathrm{C}$ in $5 \% \mathrm{CO}_{2}$ atmosphere and $95 \%$ humidity. Cell extracts were prepared, followed by immunoprecipitation and immunoblotting with specific anti-pIGF-IR, anti-pERK1/2 and anti-pAkt antibodies.

Results. After 5 minute stimulation with IGF-I, $70 \%$ of the IGF-IR was phosphorylated in the cell line CSC 1595 and 25\% in MCF-7. In addition, Akt (oncogene protein v-akt) and ERK1/2 (extracellular signal-regulated MAP kinases) were phosphorylated. Basal and stimulated levels of phosphorylated ERK1/2 were substantially higher compared to those in the MCF-7 cell line.

Conclusions. The IGF-IR and MAPK kinase pathway involving proteins ERK1/2 showed more significant phosphorylation in the 1,595 cells compared to the observed in the MCF-7 cell line. Since the IGF-IR is the major activator of this pathway it may play an important role in ductal infiltrating breast cancer tumor growth and metastases.

Key words: breast neoplasms, cell line; receptor, IGF type 1; mitogen-activated protein kinase 1, 1-phosphatidylinositol 3-kinase, oncogene protein v-akt. 
El cáncer de mama es una de las principales causas de morbilidad y mortalidad en la población femenina a nivel mundial, con importantes implicaciones en la salud pública de las sociedades modernas (1). A nivel biológico, el cáncer mamario es el resultado de una serie de alteraciones genéticas que adquieren las células del tejido epitelial mamario y que las lleva a desarrollar el fenotipo propio de células malignas, un crecimiento descontrolado, una resistencia atípica a la muerte celular y un carácter predominantemente invasivo (2).

Los factores genéticos y bioquímicos involucrados en los procesos de proliferación y muerte celular son, por tanto, los principales objetivos de estudio en la biología del cáncer. En el carcinoma mamario se han descrito algunos marcadores moleculares asociados con el fenotipo tumoral de las células malignas; estos incluyen al receptor de estrógenos (Estrogen Receptor, ER) (3), el receptor del factor de crecimiento epidérmico (EGFR/HER2) (4), el gen BRCA-1 (5), la glucoproteína E-cadherina (6) y la proteína cinasa Akt (7); todos ellos han encontrado aplicación en el diagnóstico clínico o como blancos de acción terapéutica.

Actualmente, se están adelantando investigaciones dirigidas a la evaluación de nuevos marcadores moleculares que puedan tener valor en el pronóstico y tratamiento de la enfermedad tumoral mamaria. Uno de ellos, el receptor del factor de crecimiento similar a la insulina tipo I (IGF-IR), se presenta como un factor de gran relevancia en el desarrollo y progresión del fenotipo tumoral en diversos tipos de cáncer incluido, y de manera importante, el carcinoma mamario (8).

Algunos datos experimentales sugieren que las vías de señalización asociadas al ER, al EGFR/ HER2 y al IGF-IR son interactivas. Parte de los efectos pleiotrópicos de la vía de señalización del ER pueden explicarse por el entrecruzamiento bidireccional de proteínas de señalización que comparte con las vías de estos factores de crecimiento $(9,10)$. Los estudios hacen énfasis en la importancia de este fenómeno para la etiología y progresión del cáncer de seno $(11,12)$.

\footnotetext{
Correspondencia:

Wilson Mejía, Departamento de Nutrición y Bioquímica, Facultad de Ciencias, Pontificia Universidad Javeriana, Bogotá, D.C., Colombia

Teléfono: (571) 320 8320, extensión 4104; fax: (571) 3208320 , extensión 4059

wmejia@javeriana.edu.co
}

Recibido: 22/10/09; aceptado:04/08/10
La correlación demostrada entre el IGF-IR y sus ligandos (IGF-I e IGF-II) y los procesos de transformación y progresión a un proceso celular maligno, han llevado a proponer al IGF-IR como un posible blanco farmacológico en el tratamiento del cáncer $(13,14)$. El IGF-IR está compuesto por dos cadenas de polipéptidos unidas de forma covalente, cada una de ellas con una subunidad a extracelular y una subunidad $\beta$ transmembrana, la cual tiene un dominio que posee la actividad tirosina cinasa. Cuando se une el ligando IGF-I, se induce un cambio de conformación en la subunidad $\beta$ que activa su autofosforilación; el receptor activado atrae hacia él, proteínas adaptadoras que son de la familia de los sustratos del receptor de insulina. Estas proteínas adaptadoras sirven luego como sitios de unión para otras moléculas de señalización, lo cual conlleva la activación de vías de señalización, como lo son las del fosfatidilinositol 3 cinasa (PI-3K) y las cinasas reguladas por señales extracelulares (ERK1/2) de la vía de la proteína cinasa activada por mitógenos (MAPK) (15).

La vía PI-3K está implicada, principalmente, en procesos metabólicos, de crecimiento celular y antiapoptosis. Brevemente, el IGF-IR fosforila al sustrato del receptor de insulina correspondiente (IRS1-4), el cual interactúa con la subunidad p85 (subunidad reguladora de la PI-3K de $85 \mathrm{kDa}$ ) que, a su vez, activa la subunidad p110 (subunidad catalítica de la PI-3K de $110 \mathrm{kDa}$ ), produciendo la formación de derivados de fosfolípido fosfatidilinositol-4,5-bifosfato (PIP2) que interactúan con la cinasa de serina/treonina proteína cinasa B (PKB/Akt), activándola y modulando la función de otras proteínas. Los derivados del PIP2 también provocan la activación de algunas isoformas de la proteína cinasa C (16).

La supervivencia celular es mediada no solamente por PI3K/Akt, sino también por otras vías de señalización, incluyendo la vía MAPK. Un gran número de oncogenes exhiben la activación de MAPK como una vía común. La fosforilación de IRS-1 recluta al complejo GRB2/SOS (Growth FactorReceptor-Bound Protein-2/Son Of Sevenless Proteins) del citoplasma a la membrana. Este evento se produce en proximidad a Ras (proteína oncogénica p21), lo cual cataliza el intercambio de GTP a GDP. La activación de Raf (MAP kinase kinase) mediante Ras activa la vía MAPK por fosforilación de las cinasas serina/treonina MEK1 (MAP kinase kinase), lo que conlleva la señalización "corriente abajo" con algunos sustratos 
en el citosol y otros en el núcleo. La activación de MAPK es importante para regular el ciclo celular, la proliferación y la diferenciación celular, como también procesos metabólicos (17).

El uso de modelos biológicos adecuados con diferentes características fenotípicas que puedan representar el contexto de la enfermedad tumoral in vivo, es necesario en la búsqueda de nuevas estrategias terapéuticas y de diagnóstico. Para ello es indispensable caracterizar dichos modelos, con el fin de establecer los factores esenciales relacionados con los procesos de carcinogésis y capacidad invasora del tumor, así como la posible inhibición de aquellos factores relacionados con la generación de resistencia a los tratamientos actuales.

El cáncer de mama se ha convertido en un paradigma de la investigación preclínica quimioterapéutica. Los modelos celulares derivados del carcinoma mamario son usados hoy en día, no solamente para descubrir compuestos con actividad citotóxica, sino también para tratar de establecer los mecanismos por los cuales las células tumorales desarrollan resistencia a los tratamientos actuales.

El propósito de este estudio fue caracterizar la fosforilación del receptor IGF-I tipo I y las moléculas de señalización intracelular Akt y Erk 1/2 de las vías de señalización PI-3K y MAPK, en respuesta al estímulo con el IGF-I, una línea celular nativa de cáncer de seno obtenida y establecida a partir de la biopsia de una paciente colombiana con diagnóstico clínico de carcinoma ductal infiltrante mamario $(18,19)$, con el eventual fin de aprovecharlas como modelos biológicos más específicos en ensayos preclínicos.

\section{Materiales y métodos}

\section{Líneas celulares}

La línea celular CSC 1595 (cáncer colombiano de seno) fue obtenida en el Instituto Nacional de Cancerología a partir del tumor de una paciente de 77 años con cáncer avanzado de mama ductal infiltrante, diagnosticado con las siguientes características: aneuploide-70 cromosomas, dependiente de hormonas y sensible a antraciclinas y 5-fluoro-uracilo. Como control se utilizaron las líneas celulares MCF-7: línea celular derivada de cáncer de mama (ATCC HBT-22) y B-3: línea celular fibroblastoide NIH 3T3 transfectada con el receptor IGF-IR humano, obtenida del Laboratorio de Endocrinología Molecular de los National Institutes of Health, Bethesda, Estados Unidos.
Las líneas celulares CSC 1595, B-3 y MCF-7 se cultivaron en frascos de $75 \mathrm{~cm}^{2}$ con medio DMEM con suplemento de $10 \%$ de suero fetal bovino (Invitrogen, USA) y antibióticos (penicilina 100 $\mathrm{U} / \mathrm{ml}$, estreptomicina $100 \mu \mathrm{g} / \mathrm{ml}$ ). Los cultivos celulares se incubaron a $37^{\circ} \mathrm{C}$ y en un ambiente con $5 \%$ de $\mathrm{CO}_{2}$.

\section{Análisis de proteínas por inmunoprecipitación y Western blot}

Una vez las células estaban en el $90 \%$ de confluencia, se realizaba desprendimiento con tripsina $0,25 \%$ y EDTA $1 \mathrm{mM}$. Se hicieron pases a cajas de Petri de $100 \mathrm{~mm}$, las cuales se cultivaron en las condiciones arriba descritas toda la noche hasta alcanzar, aproximadamente, $80 \%-90 \%$ de confluencia; las células $\left(2,5-3 \times 10^{6}\right)$ se cambiaron a medio sin SFB durante 2 horas y se procedió a realizar los estímulos correspondientes con IGF-I (Gropep, Australia) en concentración de $10 \mathrm{nM}$ $\left(\mathrm{kDa}=10^{-9}-10^{-8} \mathrm{M}\right)$.

Cumplido el tiempo específico de estímulo (5, 10, 30 y 60 minutos), se lavaron con PBS frío y se incubaron en solución de lisis [Tris-Cl $50 \mathrm{mM} \mathrm{pH}$ 7,4; $\mathrm{NaCl} 150 \mathrm{mM}$; EDTA $1 \mathrm{mM}$, CHAPS 1\%, NaF 2 $\mathrm{mM}$, pirofosfato de sodio $10 \mathrm{mM}, \beta$-glicerofosfato 8 $\mathrm{mM}$, ortovanadato de sodio $1 \mathrm{mM}$, con suplemento de una tableta de coctel de inhibidores de proteasas (Roche)]. El lisado celular se centrifugó a $13.000 \mathrm{rpm}$ durante 10 minutos y se obtuvo el sobrenadante; se determinó la concentración de proteína por el método del ácido bicinconínico y se guardó a $-30^{\circ} \mathrm{C}$.

Para el estudio de la fosforilación del IGF-IR, se inmunoprecipitó $1 \mathrm{mg}$ de proteína, se adicionó el anticuerpo específico anti-IGF-IR, $3 \mu \mathrm{g} / \mathrm{mg}$ proteína (C-20 Santa Cruz Biotechnology, USA) y se incubó a $4{ }^{\circ} \mathrm{C}$ toda la noche. El complejo se inmunoprecipitó con proteína G sefarosa (GE Health Care, USA) al $30 \%$ incubando por 4 horas a $4{ }^{\circ} \mathrm{C}$ con agitación circular seguida de centrifugación a 13.000 rpm por

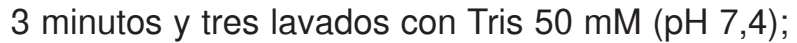
el precipitado se volvió a suspender en solución tampón laemli [Tris-Cl 500 mM pH 6,8; SDS 10\%; glicerol $50 \% ; \beta$-mercaptoetanol $5 \%$ y azul de bromofenol $1 \%$, con suplementde con ditiotreitol (DTT) $100 \mathrm{mM}$, el cual se calentó a $96{ }^{\circ} \mathrm{C}$ por 5 minutos.

El sobrenadante se sometió a electroforesis SDSPAGE en gel al $8 \%$. Las proteínas se transfirieron a membranas de nitrocelulosa y se bloqueó con leche descremada al $5 \%$. Posteriormente, 
la membrana se incubó toda la noche a $4^{\circ} \mathrm{C}$ con anticuerpo específico anti-fosfotirosina (P-Tyr-100 \# 9411Upstate, Cell Signaling, dilución 1:2000) se eliminó el exceso de anticuerpo mediante lavados consecutivos con TTBS (Tris-Cl 20mM pH 7,4; $\mathrm{NaCl} 150$ mM, Tween 20 0,05\%) y se procedió al sistema de inmunodetección descrito abajo.

Para las proteínas Akt y ERK1/2, no se realizó immunoprecipitación; en este caso, $50 \mu \mathrm{g}$ de cada extracto celular de acuerdo con el tiempo de estímulo se volvió a suspender en solución tampón carga con suplemento de con DTT, calentado a 96 ${ }^{\circ} \mathrm{C}$ y luego sometido a electroforesis en gel al $10 \%$. La transferencia se realizó como está descrito arriba. La detección de las proteínas fosforiladas ERK1/2 y Akt se hizo con anticuerpos anti-fosfop44/42 Thr 202/Tyr204, dilución 1:1000, y antifosfo-Akt Ser473, dilución 1:500, respectivamente (Upstate, Cell Signaling, USA).

Para determinar la proteína total (IGF-IR, ERK1/2 y Akt), la membrana se lavó para remover los respectivos anticuerpos (Re-Blot Plus, Chemicon Internacional, USA), se bloqueó nuevamente y se procedió a incubar con anticuerpo específico anti IGFIR, dilución 1:500 (C-20 Santa Cruz Biotechnology, USA), anti Akt y anti p44/42, ambos en dilución 1:1000 (Upstate, Cell Signaling, USA) y detección con el sistema de quimioluminiscencia ECL (GE, USA).

La detección se hizo incubando previamente con un anti-lgG de conejo (Amershan, dilución 1:10000), excepto para antifosfotirosina, anti-lgG de ratón (Dako, dilución 1: 3000), acoplados a peroxidasa de rábano HRP seguido de la adición del sustrato y revelado. La cuantificación de la señal se realizó por densitometría (Quantity One, Biorad).

El presente estudio fue avalado por el Comité de Ética de la Facultad de Ciencias de la Pontificia Universidad Javeriana.

\section{Análisis estadístico}

Los resultados de señalización intracelular se expresan como el valor medio \pm Standard Error of the Mean (SEM) de tres experimentos. La significancia estadística se evaluó con la prueba $t$ de Student para datos pareados.

\section{Resultados}

Detección del receptor IGF tipo I (IGF-IR) fosforilado en respuesta al estímulo con el IGF-I

La presencia del receptor IGF de tipo 1 y su fosforilación se verificaron en la línea celular
CSC 1595. Como control se utilizaron las líneas celulares MCF-7 y B-3. Las células B-3 (NIH-3T3 transfectadas con el gen del receptor humano de IGF-I) fueron utilizadas como control de fosforilación.

En la figura $1 \mathrm{~A}$ se observa para las líneas celulares, la presencia del receptor en el tiempo 0 , control no estimulado, en su estado basal de fosforilación; cinco minutos después del estímulo, se observa la fosforilación del mismo. La figura 1B muestra el control de carga de proteína. Los resultados muestran que la fosforilación es mayor en la línea celular CSC 1595 que en la MCF-7. El análisis de densitometría (figuras 1C y 1D) muestra que a los 5 minutos de estímulo con IGF-I, $70 \%$ y $25 \%$ del receptor se encuentras fosforilados en las células CSC 1595 y MCF-7, respectivamente $(p<0,001)$. La respuesta a los 10 y 30 minutos es similar a la observada a los 5 minutos. Una hora después del estímulo, el $100 \%$ del receptor en la línea CSC 1595 se encuentra fosforilado, mientras que en la MCF-7 sólo lo está el 35\% ( $p<0,001)$.

\section{Detección de las proteínas fosforiladas ERK1/2 y AKT en respuesta al estímulo con el IGF-I}

Los resultados muestran que hay una respuesta al estímulo con el IGF-I determinada por la fosforilación de las proteínas de señalización intracelular de las dos vías de señalización, PI-3K y MAPK, en la línea celular CSC 1595. La proteína Akt mantiene niveles similares basales de fosforilación en las líneas celulares CSC 1595 y MCF-7 (figura 2A, tiempo 0) y el IGF-I estimula un incremento de 4 a 5 veces respecto a los controles no estimulados en ambas líneas celulares ( $p<0,001)$. Se observa también que los niveles totales de la proteína Akt son similares tanto en MCF-7 como en CSC 1595. No se observó diferencia estadística.

Se observa diferencia significativa $(p<0,001)$ en la fosforilación de las proteínas ERK1 y ERK2, a los 5 y 10 minutos del estímulo con IGF-I en las líneas celulares CSC 1595 y MCF-7, comparadas con sus respectivos niveles basales (figura 2B). De gran interés es el hallazgo de que las proteínas ERK1/2 mantienen un nivel de fosforilación basal estadísticamente significativo mayor (3,5 a 4,5 veces), al tiempo 0 en células CSC 1595, que el observado en células de la línea MCF-7 (figura 2C).

\section{Discusión}

Éste es el primer estudio de caracterización molecular de las vías de señalización MAPK y PI3K asociadas a la fosforilación del IGF-IR en la 
A. $97 \mathrm{kD}$
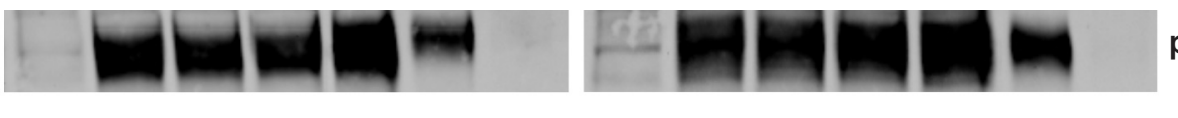

pIGF-IR

B.

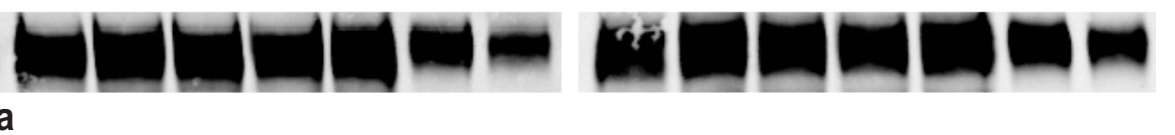

IGF-IR

$97 \mathrm{kDa}$

\begin{tabular}{|l|c|c|c|c|c|c|c|c|c|c|c|c|c|c|}
\hline Tiempo $(\mathrm{min})$ & 0 & 5 & 10 & 30 & 60 & 5 & 0 & 0 & 5 & 10 & 30 & 60 & 5 & 0 \\
\hline Línea celular & \multicolumn{10}{|c|}{ MCF-7 } \\
\hline
\end{tabular}

C.

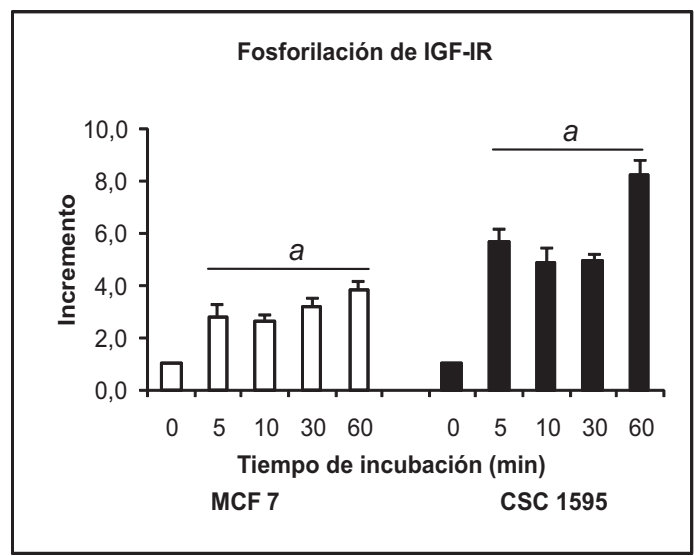

D.

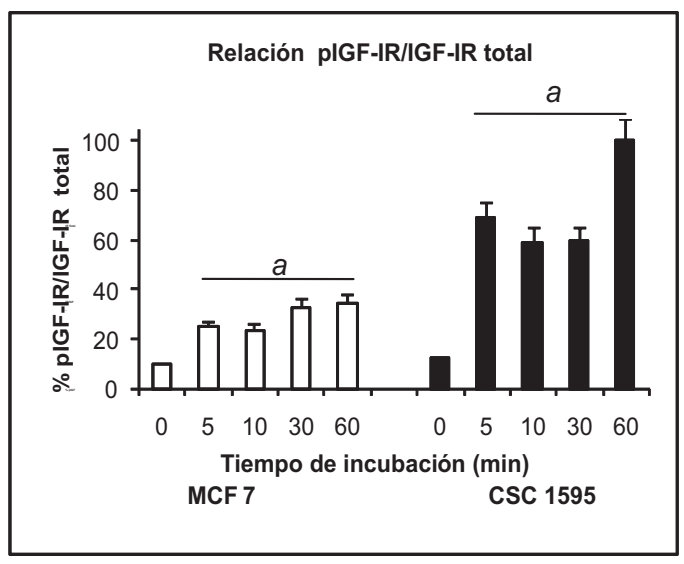

Figura 1. Identificación del IGF-IR y su activación en respuesta al estímulo por el IGF-I en tres líneas celulares. Los extractos celulares, la inmunoprecipitación y el Western blotting se realizaron como está descrito en materiales y métodos.

A) Análisis por Western blot que muestra la banda de peso molecular 97 kDa detectada con el anticuerpo anti-fosfotirosina.

B) Banda correspondiente a IGF-IR total detectada con el anticuerpo anti-IGF-IR; corresponde al control de carga.

C) Análisis densitométrico de las bandas de fosforilación de IGF-IR. Las veces de incremento se toman como referencia al valor a tiempo de estímulo cero minutos (control de normalización para las líneas celulares MCF-7 y CSC 1595).

D) Relación en porcentaje del IGF-IR fosforilado respecto al IGF-IR total para cada uno de los tiempos de estímulo en las líneas celulares MCF-7 y CSC 1595.

Los valores corresponden a la media \pm SEM (Standard Error of the Mean) de 3 experimentos.

a $p<0,001$ comparado al tiempo 0 en cada línea celular. Las barras negras corresponden a la línea celular CSC 1595 y las vacías a la línea MCF-7.

línea celular CSC 1595 derivada de un carcinoma mamario, la cual responde de forma similar a la línea celular MCF-7, también derivada de cáncer de mama y utilizada por la comunidad científica en estudios de cáncer mamario (20).

Los estudios de fosforilación del receptor IGF de tipo 1 en la línea celular MCF-7 muestran que, a los 5 minutos de estímulo con IGF-I, un $25 \%$ del receptor se fosforila, respecto al receptor total y, a una hora, el 35\% permanece fosforilado, mientras que en la línea CSC 1595 estos valores son de $69 \%$ y $100 \%$, respectivamente. Los resultados demuestran que es un fenómeno debido al estímulo con el IGF-I, ya que en ambas líneas celulares la fosforilación basal del receptor fue similar y estuvo alrededor del $10 \%$ (figuras $1 \mathrm{~A}$ y
1D). La fosforilación del IGF-IR como respuesta al estímulo del IGF-I, además de una función mitogénica, protege a las células de una variedad de señales de apoptosis, induce diferenciación en ciertos tipos de células y tiene un rol crucial en el establecimiento y mantenimiento del fenotipo transformado (15). Algunos intermediarios en la cascada de activación de IGF-IR se han vinculado con los efectos antiapoptosis y mitogénicos. En particular, las vías de transducción de la señal activadas por la proteína cinasa de fosfolípidos PI-3K (21) y por la proteína cinasa activada por mitógenos MAPK, median la respuesta celular al estímulo con IGF-I en células cancerosas (22).

La detección de la fosforilación de la proteína Akt es el primer paso en la caracterización de la vía 
A.

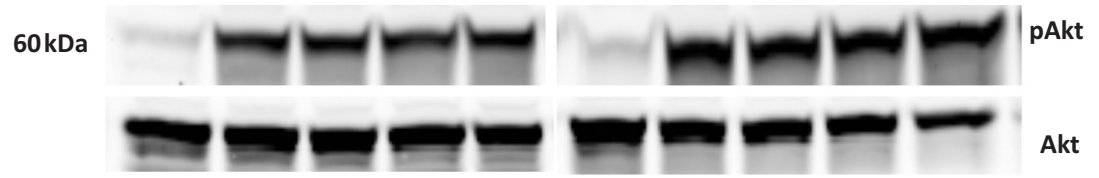

B.

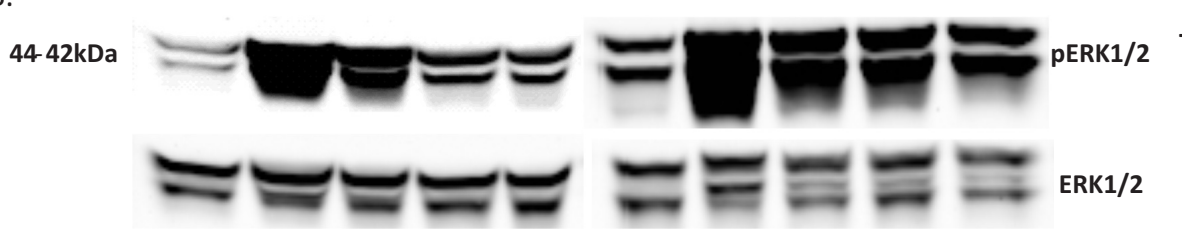

\begin{tabular}{|l|c|c|c|c|c|c|c|c|c|c|}
\hline Tiempo $(\mathrm{min})$ & 0 & 5 & 10 & 30 & 60 & 0 & 5 & 10 & 30 & 60 \\
\hline Línea celular & \multicolumn{9}{|c|}{ MCF-7 CSC 1595 } \\
\hline
\end{tabular}

C.
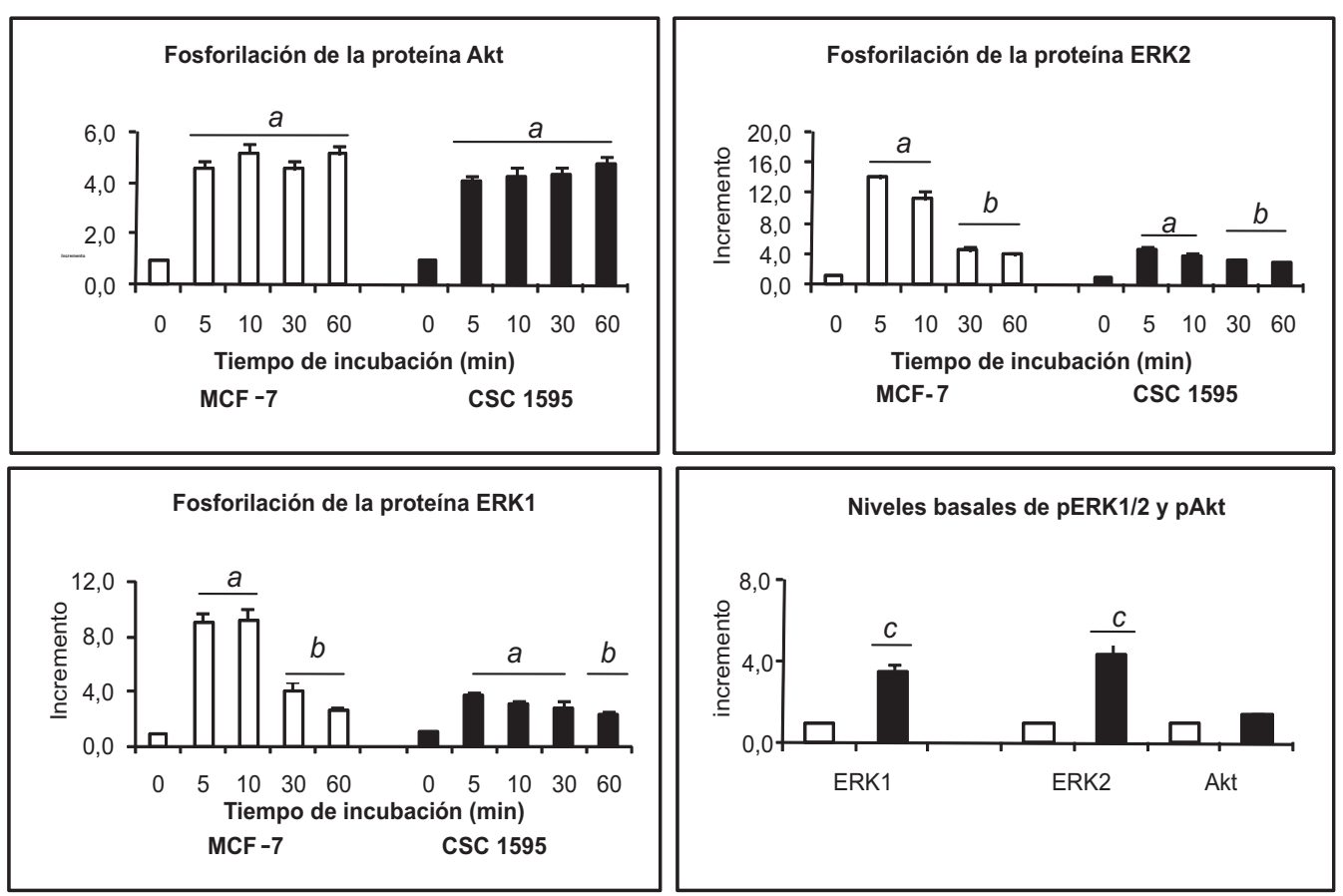

Figura 2. Identificación de la activación de las vías de señalización PI-3K y MAPK activadas por el estímulo con IGF-I en las células CSC 1595 y MCF-7. Se siguió la metodología descrita en materiales y métodos.

A) Análisis por Western blot de la fosforilación usando el anticuerpo anti-pAkt Ser473 y de la proteína total con anti-Akt total.

B) Western blot de la fosforilación de ERK1/2 utilizando el anticuerpo anti-p44/42 Thr 202/Tyr204 y la proteína total con anti-p44/42 total.

C) Análisis densitométrico del nivel de fosforilación de pAkt, pERK1 y pERK2 y niveles basales de proteínas fosforiladas.

La relación en incremento se midió con respecto al valor en tiempo 0 minutos. Los valores corresponden a la media \pm SEM (Standard Error of the Mean) de tres experimentos.

${ }^{a} p<0,001$ comparado al tiempo 0 en cada línea celular; ${ }^{b} p<0,01$ comparado al tiempo 0 en cada línea celular; ${ }^{c} p<0,001$ comparado a la línea celular MCF-7. Las barras negras corresponden a CSC 1595 y las vacías a MCF-7.

de señalización dirigida por la PI-3K. En nuestro estudio encontramos que ambas líneas celulares tienen un nivel basal similar de fosforilación, que corresponde a $10 \%$ de la proteína total (figuras $2 \mathrm{~A}$ y $2 \mathrm{C}$ ). Es de interés notar que, mientras que en la línea MCF-7 a los 5 y 60 minutos el nivel de fosforilación corresponde a $30 \%$ y $40 \%$, en la línea
CSC 1595 estos valores corresponden a 68\% y $100 \%$. Los anteriores valores son similares a los encontrados para la fosforilación del receptor de IGF de tipo 1. La vía de señalización PI-3K regula funciones celulares tales como crecimiento celular, supervivencia y migración. La proteínaAkt, conocida también como proteína cinasa $B$, se fosforila en 
residuos de serina y treonina como respuesta a los estímulos de factores de crecimiento en una manera que depende de la PI-3K. Esta proteína puede ser activada por proteínas IRS o a través de la vía de señalización de la oncoproteína Ras, que también actúa como transductor de la señal generada por la estimulación del IGF-I o la insulina a su receptor (23). Ras es la molécula común más próxima al receptor activado que sirve para varias vías de señalización, tales como la Ras/Raf/MEK/ ERK (MAPK), PI-3K/Akt y otras vías con función apoptósica.

En general, se sabe que la vía MAPK tiene diversos efectos, tales como regular el ciclo celular, la apoptosis y la diferenciación celular (17). En este estudio de caracterización encontramos una mayor actividad de las proteínas ERK1/2 en la línea celular CSC 1595, en comparación con la MCF-7 (figuras 2B y $2 \mathrm{C}$ ). En las dos líneas celulares se observa claramente que hay un incremento significativo en la fosforilación para ambas proteínas. De gran interés es el hallazgo de un nivel mayor de fosforilación basal en la línea CSC 1595 y la mayor respuesta al estímulo con IGF-I en comparación con la MCF-7. Se ha demostrado que la activación de las proteínas ERK1/2 es crítica para la supervivencia de las líneas celulares derivadas del cáncer de mama, lo que ha sugerido que esta vía representa el mejor blanco para la terapia en cáncer (24). La línea celular CSC 1595 se muestra muy promisoria para subsecuentes estudios, dada la mayor actividad de la vía MAPK y la importancia de esta vía en el ciclo y la diferenciación celulares.

La línea celular CSC-1595 es dependiente de hormonas y se sabe que algunas cinasas intracelulares de las vías PI-3K y MAPK tienen la capacidad de fosforilar al receptor de estrógeno y estimular su actividad de transcripción de manera dependiente del ligando (25). Se ha reportado que la activación del IGF-IR y su señalización asociada incrementan la señalización del ER en tumores que responden a terapia con tamoxifeno; mientras que, en tumores resistentes al fármaco, se ha visto que la actividad mitogénica es facilitada por medio del EGFR (26). Lo anterior sugiere la importancia de considerar al IGF-IR y las vías de señalización activadas como blancos de estudio en líneas celulares o tumores positivos para el ER.

La caracterización de los sistemas reguladores de los factores de crecimiento en líneas celulares es actualmente una prioridad en la investigación en cáncer de mama, al ser éste uno de los más frecuentes a nivel mundial y el segundo más común de los tipos de cáncer en Colombia (27). Su estudio cobra una gran importancia en la búsqueda de marcadores bioquímicos y genéticos de la enfermedad, que puedan usarse como blancos terapéuticos.

La aplicación de un tratamiento efectivo basado en la inhibición de la actividad del IGF-IR y la supresión de las cascadas de señalización desencadenadas por éste, dependerá en gran medida de la validación del IGF-IR en términos de su nivel de expresión y su funcionalidad biológica en los diferentes tipos de tumores en los cuales puede tener relevancia en la progresión del cáncer, como el carcinoma mamario (28).

Aunque los resultados del presente trabajo no son suficientes para concluir sobre el papel del IGFIR en los procesos de diferenciación y metástasis de tumores, es necesario continuar con la caracterización de la línea celular CSC 1595, de forma tal que se llegue a determinar el número de receptores en membrana celular para el IGF-I, IGFII e insulina; además, estudiar la activación de las proteínas asociadas IRS y la respuesta de activación de las vías de señalización PI-3K y MAPK al estímulo con insulina e IGF-I. De igual forma, es necesario investigar los mecanismos de interacción de estas vías de señalización con fármacos antitumorales y correlacionarlos con otros estudios realizados en la línea celular CSC 1595 (18).

\section{Agradecimientos}

Agradecemos al Instituto Nacional de Cancerología por facilitar la línea celular CSC 1595 y a Derek LeRoith por facilitar la línea celular B-3.

\section{Conflicto de intereses}

Los autores manifiestan que no existe conflicto de intereses en la elaboración y ejecución de este proyecto y la publicación de este artículo.

\section{Financiación}

El proyecto fue financiado por la Fundación para la Promoción de la Ciencia y la Tecnología del Banco de la República y la Pontificia Universidad Javeriana (P-1978).

\section{Referencias}

1. Key TJ, Verkasalo PK, Banks E. Epidemiology of breast cancer. Lancet Oncol. 2001;2:133-40.

2. Riley L, Desai D. The molecular basis of cancer and the development of targeted therapy. Surg Clin North Am. 2009;89:1-15. 
3. Hurvitz S, Pietras R. Rational management of endocrine resistance in breast cancer: A comprehensive review of estrogen receptor, treatment options and future directions. Cancer. 2008;113:2385-97.

4. Milanezi F, Carvalho S, Schmitt FC. EGFR/HER2 in breast cancer: a biological approach for molecular diagnosis and therapy. Expert Rev Mol Diagn. 2008;8:417-34.

5. Nicoletto MO, Donach M, Nicolo AD, Artioli G, Banna G, Monfardini S. BRCA-1 and BRCA-2 mutations as prognostic factors in clinical practice and genetic counselling. Cancer Treat Rev. 2001;27:295-304.

6. Hirohashi S, Kanai Y. Cell adhesion system and human cancer morphogenesis. Cancer Sci. 2003;94:575-81.

7. Troussard AA, McDonald PC, Wederell ED, Mawji NM, Filipenko NR, Gelmon KA, et al. Preferential dependence of breast cancer cells versus normal cells on integrin-linked kinase for protein kinase B/Akt activation and cell survival. Cancer Res. 2006;66:393-403.

8. Pezzino V, Papa V, Milazzo G, Gliozzo B, Russo P, Scalia P. Insulin-like growth factor-I (IGF-I) receptors in breast cancer. Ann NY Acad Sci. 1996;784:189-201.

9. Gee JM, Robertson JF, Gutteridge E, Ellis IO, Pinder SE, Rubini M, et al. Epidermal growth factor receptor/HER2/ insulin-like growth factor receptor signalling and oestrogen receptor activity in clinical breast cancer. Endocr Relat. 2005;12:S99-111.

10. Massarweh S, Osborne CK, Creighton CJ, Qin L, Tsimelzon A, Huang S, et al. Tamoxifen resistance in breast tumors is driven by growth factor receptor signaling with repression of classic estrogen receptor genomic function. Cancer Res. 2008;68:826-33.

11. Schiff R, Massarweh SA, Shou J, Bharwani L, Mohsin SK, Osborne CK. Cross-talk between estrogen receptor and growth factor pathways as a molecular target for overcoming endocrine resistance. Clin Cancer Res. 2004;10:331s-6s.

12. Nicholson RI, Hutcheson IR, Knowlden JM, Jones HE, Harper ME, Jordan N, et al. Nonendocrine pathways and endocrine resistance. Clin Cancer Res. 2004;10:346s-54s.

13. Lann $\mathbf{D}$, LeRoith $\mathbf{D}$. The role of endocrine insulin-like growth factor-I and insulin in breast cancer. J Mammary Gland Biol Neoplasia. 2008;13:371-9.

14. Yu H, Rohan T. Role of the insulin-like growth factor family in cancer development and progression. J Natl Cancer Inst. 2000;92:1472-89.

15. LeRoith D, Roberts CT. The insulin-like growth factor system and cancer. Cancer Lett. 2003;195:127-37.
16. Yanochko G, Eckhart W. Type I insulin-like growth factor receptor over-expression induces proliferation and antiapoptotic signaling in a three-dimensional culture model of breast epithelial cells. Breast Cancer Res. 2006;8:R18.

17. Sun $\mathbf{H}$, Tu $\mathbf{X}$, Baserga $\mathbf{R}$. Dual regulation of upstream binding factor 1 levels by IRS-1 and ERKs in IGF-1-receptor signaling. J Cell Physiol. 2007;212:780-6.

18. Castro C, Riveros T, Jiménez G, Téllez N. Inducción de apoptosis por el principio activo citotóxico de Espeletia killipii Cuatr. sobre líneas celulares humanas. Rev Bras Farmacogn. 2007;17:497-500.

19. Castro C, Riveros T. Registro del Laboratorio de Biología Experimental. Bogotá, D. C.: Instituto Nacional de Cancerología E. S. E.; 1999.

20. Dickson RB, Bates SE, McManaway ME, Lippman ME. Characterization of estrogen responsive transforming activity in human breast cancer cell lines. Cancer Res. 1986;46:1707-13.

21. Frasca F, Pandini G, Sciacca L, Pezzino V, Squatrito S, Belfiore A, et al. The role of insulin receptors and IGF-I receptors in cancer and other diseases. Arch Physiol Biochem. 2008;114:23-37.

22. Sarfstein R, Maor S, Reizner N, Abramovitch S, Werner H. Transcriptional regulation of the insulin-like growth factor-I receptor gene in breast cancer. Mol Cell Endocrinol. 2006;252:241-6.

23. Dillon RL, White DE, Muller WJ. The phosphatidyl inositol 3-kinase signaling network: implications for human breast cancer. Oncogene. 2007;26:1338-45.

24. Whyte J, Bergin O, Bianchi A, McNally S, Martin F. Key signalling nodes in mammary gland development and cancer. Mitogen-activated protein kinase signalling in experimental models of breast cancer progression and in mammary gland development. Breast Cancer Res. 2009;11:209.

25. Lannigan DA. Estrogen receptor phosphorylation. Steroids. 2003;68:1-9.

26. Gee JM, Howell A, Gullick WJ, Benz CC, Sutherland RL, Santen RJ, et al. Consensus statement. Workshop on therapeutic resistance in breast cancer: impact of growth factor signalling pathways and implications for future treatment. Endocr Relat Cancer. 2005;12:S1-7.

27. Piñeros M, Ferlay J, Murillo R. Cancer incidence estimates at the national and district levels in Colombia. Salud Pública Mex. 2006;48:455-65.

28. Baserga R. Customizing the targeting of IGF-1 receptor. Future Oncol. 2009;5:43-50. 